\title{
Thermodynamic Analysis of a Diesel Exhaust Wet Scrubber
}

\author{
A. Abdulwahid ${ }^{1,2}$, R. Situ ${ }^{1}$, R. Brown ${ }^{3}$, and W. Lin ${ }^{1}$ \\ ${ }^{1}$ College of Science and Engineering \\ James Cook University, Townsville QLD 4811, Australia \\ ${ }^{2}$ Al-Nahrain University, Baghdad, 10072, Iraq \\ ${ }^{3}$ School of Mechanical Medical \& Process Engineering \\ Queensland University of Technology, Brisbane QLD 4000, Australia
}

\begin{abstract}
A wet scrubber is an air pollution removal device that eliminates particulate matter and acid gases from a diesel engine. The exhaust gas enters the scrubber beneath the liquid surface, causing a reduction in gas temperature and increases the relative humidity of the scrubber outlet. In this study, a wet scrubber was investigated experimentally based on a transient heat loss and steady-state heating process. A transient heat loss experiments were performed to estimate the heat loss from the scrubber surface. The steady-state heating process was investigated separately with various inlet gas temperatures and flow rates. The experimental results confirmed that the scrubber effectively reduces the inlet gas temperature from $650^{\circ} \mathrm{C}$ to about $50^{\circ} \mathrm{C}$. However, the outlet gas relative humidity increased due to the high liquid evaporation rate. A thermodynamic analysis estimated the outlet gas relative humidity and compares it with the measured values. The contribution of this study is: heat loss estimation methodology and relative humidity calculations.
\end{abstract}

\section{Keywords}

Wet Scrubber, Thermodynamics, Heat transfer, Humidity.

\section{Introduction}

Wet scrubbers are an air pollution removal device used for physical separation and removal of particles from the stream of exhaust gases. The thermodynamic analysis based on steadystate assumption was used previously to evaluate the energy balance for the wet scrubber [1]. Situ et al. [1] showed that the gas temperature increment at the scrubber exit corresponds to the relative humidity reduction. The same approach was used to investigate bubble columns [2]. However, the thermodynamic analysis based on the transient-state assumption [3] confirmed that the exiting gases carry some scrubbing liquid, due to turbulence, which might damage the Diesel Particulate Filter (DPF), and increase the production/maintenance cost. This paper analyses the wet scrubber experimentally and thermally at steady-state conditions to estimate the exit relative humidity.

\section{Experimental setup}

The experimental facility is shown in Figure 1. It is a 316 stainless steel tank with front and rear sides are made from a transparent high-temperature resistant Polycarbonate. It is also equipped with an industrial hot air blower. This blower supplies a maximum gas temperature $650^{\circ} \mathrm{C}$ at 113.3 Standard Litres Per Minute (SLPM) of the inlet gas. This flow rate is measured by a Dwyer rotameter. Filtered air from the laboratory lines is used as the inlet gas. This gas enters the scrubber via a $49 \mathrm{~mm}$ inlet diameter steel pipe. An orifice plate of $3 \mathrm{~mm}$ thickness 316 stainless steel sheeting contains 100 orifices. This number of orifices is essential to maintain the same crosssection area as the inlet pipe diameter and avoid back pressure generation. The gas phase leaves the experimental facility through the exit with higher relative humidity and lower temperature than the inlet condition. Several thermocouples are placed at different locations and connected to a Picolog data logger and to a laptop. These locations are: within the liquid (to consider the average temperature), above and below the liquid surface for Polycarbonate and metal scrubber sides, the outlet gas at the scrubber exit, and the ambient temperature. A Thermoworks humidity probe measures the relative humidity effectively. The scrubber tank was cleaned previous to the experimentation to remove any possible contaminant, then filled with fresh demineralized water. Liquid phase (water) was maintained at constant volume and temperature to exclude their possible effect on the scrubber performance. To check the evaporation rate, the liquid level inside the scrubber was scaled before and after each test.

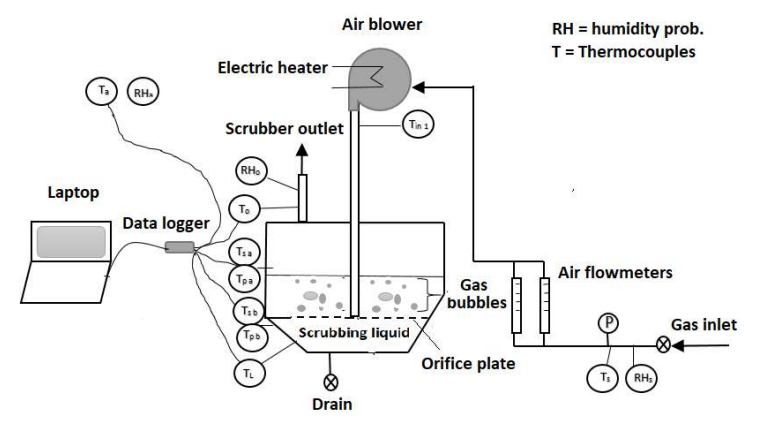

Figure 1. A wet scrubber schematic diagram.

\section{Steady-state thermodynamic analysis}

The steady-state thermodynamic analysis of the scrubber consists of energy balance according to the first law of thermodynamics and a mass balance, as shown in Figure 2. The energy equation balances between the inlet and the outlet energies including the boundaries:

$$
\dot{E}_{\text {in }}=\dot{E}_{\text {out }}+\dot{E}_{\Delta v}+Q_{L},
$$

where: $\dot{E}_{\text {in }}$ is the inlet gas power, $\dot{E}_{\text {out }}$ is the outlet gas power, $\dot{E}_{\Delta v}$ is the lost power due to liquid evaporation and $Q_{L}$ is the heat transfer from the scrubber to the surrounding. 


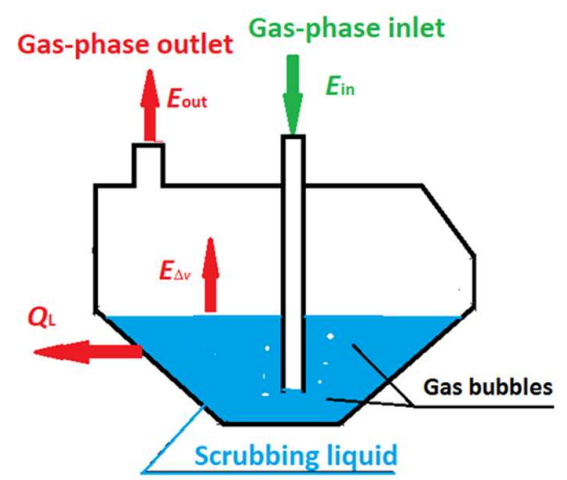

Figure 2. The energy balance of a wet scrubber.

The inlet and outlet energies were calculated based on the air components, which include oxygen $\left(\mathrm{O}_{2}\right)$, nitrogen $\left(\mathrm{N}_{2}\right)$ and water vapour $\left(\mathrm{H}_{2} \mathrm{O}\right)$ :

$$
\begin{aligned}
& \dot{E}_{\text {in }}=\left(\dot{m}_{\mathrm{H}_{2} \mathrm{O}} h_{\mathrm{H}_{2} \mathrm{O}}\right)_{\text {in }}+\left(\dot{m}_{\mathrm{O}_{2}} h_{\mathrm{O}_{2}}\right)_{\text {in }}+\left(\dot{m}_{\mathrm{N}_{2}} h_{\mathrm{N}_{2}}\right)_{\text {in }}, \\
& \dot{E}_{\text {out }}=\left(\dot{m}_{\mathrm{H}_{2} \mathrm{O}} h_{\mathrm{H}_{2} \mathrm{O}}\right)_{\text {out }}+\left(\dot{m}_{\mathrm{O}_{2}} h_{\mathrm{O}_{2}}\right)_{\text {out }}+\left(\dot{m}_{\mathrm{N}_{2}} h_{\mathrm{N}_{2}}\right)_{\text {out }},
\end{aligned}
$$

where $m$ is the mass flow rate and $h$ is the specific enthalpy.

Increasing the inlet gas temperature warms the liquid and leads to a phase change from liquid to vapour. If the liquid condensation at the scrubber inside is ignored, the energy loss due to liquid evaporation can be calculated by:

$$
\dot{E}_{\Delta v}=\dot{m}_{\Delta v} h_{f g},
$$

where $\dot{m}_{\Delta v}=\left(\dot{m}_{\mathrm{H}_{2} \mathrm{Oout}}-\dot{m}_{\mathrm{H}_{2} \mathrm{Oin}}\right)$ is the liquid mass change rate due to evaporation in and $h_{f g}$ is the liquid latent heat.

\section{Heat Loss Estimation}

The heat loss through the scrubber sides was obtained from the transient cooling experiments. The temperatures of the various parts of the scrubber were recorded. The heat loss of the scrubber at a given temperature should be equal to the energy loss due to the transient cooling (by ignoring minor losses):

$Q_{L}=\rho_{l} V_{l} c_{p l} \frac{d T_{l}}{d t}+\rho_{g} V_{g} c_{p g} \frac{d T_{o}}{d t}+m_{s} C_{p s} \frac{d T_{s}}{d t}+m_{p} C_{p p} \frac{d T_{p}}{d t}$,

where: the terms on the right side represent the liquid energy reduction, the gas upper the liquid, the stainless steel sides, and the transparent polycarbonate sides, respectively.

Heat loss experiments consist of warming up the liquid to $80^{\circ} \mathrm{C}$ without supplying the gas using a portable heating element. The liquid was kept at this temperature for a specific time then let cool down. This procedure was repeated several times for initial liquid temperatures $75^{\circ} \mathrm{C}, 70^{\circ} \mathrm{C}, 65^{\circ} \mathrm{C}$ and $60^{\circ} \mathrm{C}$, respectively. Figure 3 shows the measured temperature at various positions (liquid, outlet, ambient, upper stainless steel side, lower stainless steel side, upper polycarbonate side, lower polycarbonate side).

Heat can leave the scrubber from the outside surfaces in two possible methods, radiation and/or convection as shown in the following equation [4]:

$$
Q_{L}=A\left[h\left(T-T_{a}\right)+\epsilon \sigma\left(T^{4}-T_{a}^{4}\right)\right]
$$

where $A$ is the surface area, $h$ is the convection heat transfer coefficient, $T$ is the side temperature, $\epsilon$ is the side emissivity, and $\sigma$ is the Stefan-Boltzmann constant.

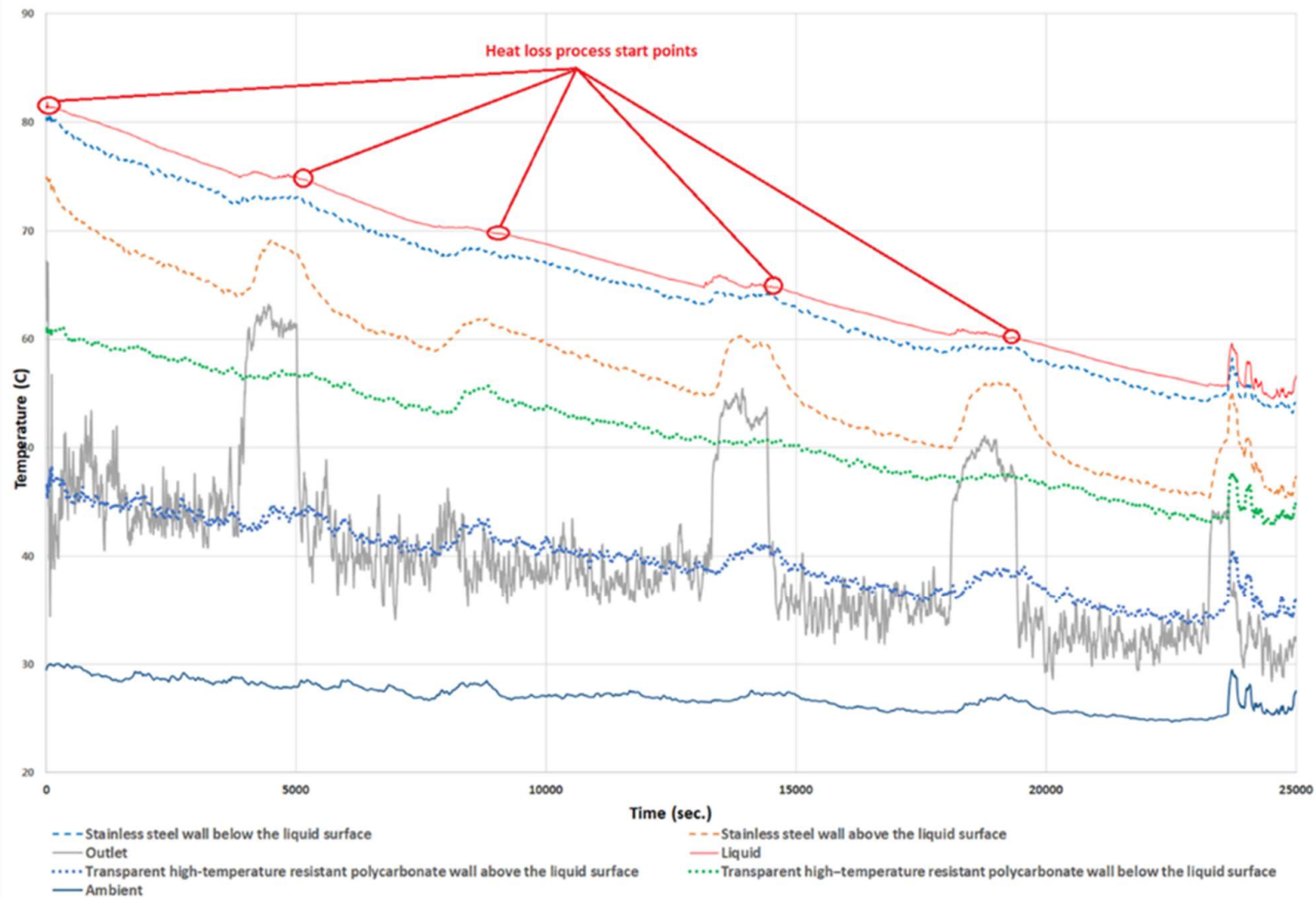

Figure 3. Temperature measurement in transient cooling experiment. 
However, the heat loss cannot be calculated directly using Equation 6. The temperature curves in Figure 3 were fitted with a fifth degree polynomial function. The derivative of this $5^{\text {th }}$ degree function compared with Equation 6 to obtain the most heat transfer method. It was found that the radiant heat transfer represented $0.4 \%$ of the total heat loss. Therefore, only the conventional heat transfer was considered.

The energy loss terms in Equation 5 can be calculated separately. It was found that the majority of the energy loss $(87 \%)$ comes from the liquid, while the energy loss from the gas above the liquid, steel side and polycarbonate sides are $1 \%$, $4.5 \%$, and $5.5 \%$, respectively. Based on this method, the major heat loss from the scrubber comes from the liquid because the liquid has a higher heat capacity and a largest mass than the gas.

The estimated heat loss from the scrubber is plotted against the liquid temperature in Figure 4. It shows that the heat loss increases due to increasing the liquid temperature because of the temperature difference increment between the liquid and the ambient. Two data points $\left(80^{\circ} \mathrm{C}\right.$ and $\left.70^{\circ} \mathrm{C}\right)$ are not included in the figure, because temperature was not maintained steadily before the starting of cooling down. A linear equation is the simplest fit to estimate the heat loss, in Equation 7. This correlation can be used to estimate the heat loss from this scrubber only because it is in a dimensional form.

$$
Q_{L}=0.113 T_{l}-5.1
$$

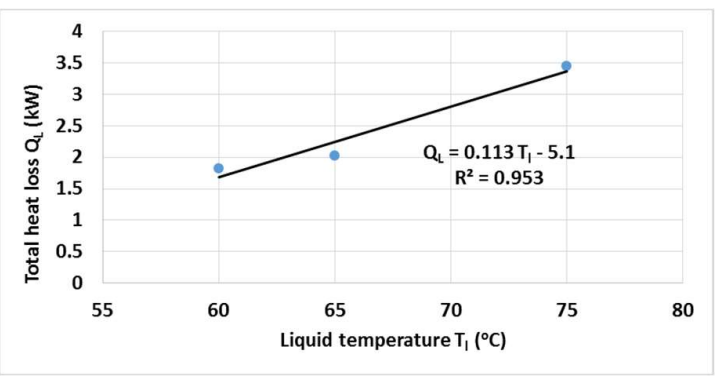

Figure 4. Relation between heat loss and liquid temperature.

\section{Free Convectional Heat Transfer Coefficient}

The free convection heat transfer coefficient between the scrubber and its surroundings was assumed as a constant value. It can be calculated using two different methods. The first one depends on the heat loss from all of the scrubber components and the liquid as:

$$
Q_{L}=h A(\Delta T)
$$

The free heat transfer coefficient also can be calculated using some empirical correlations such as Churchill \& Chu [5]:

$$
\overline{N u}=\frac{h L}{k}=\left[0.825+\frac{0.387 \mathrm{Ra}^{1 / 6}}{\left(1+\left(\frac{0.492}{\mathrm{Pr}}\right)^{9 / 16}\right)^{8 / 27}}\right]^{2}
$$

where: $\overline{N u}$ is the mean Nusselt number, Ra is the Rayleigh number and $\mathrm{Pr}$ is the Prandtl number.

The free convection heat transfer coefficients calculated from Equations 8 and 9 are presented in Table 1. This also confirms that the heat loss estimation at the initial liquid temperatures of $80^{\circ} \mathrm{C}$ and $70^{\circ} \mathrm{C}$ were excessively high comparing with empirical correlation. This confirms the removal of these two data points for Equation 7 was necessary.

\begin{tabular}{cccc}
\hline $\begin{array}{c}\text { Initial } \\
\mathbf{T}_{\boldsymbol{l}}\left(\mathbf{o}^{\circ} \mathbf{C}\right)\end{array}$ & $\begin{array}{c}\boldsymbol{h}_{\boldsymbol{e x p}} \text { Equation } 8 \\
\left(\mathrm{~W} / \mathrm{m}^{2} \cdot \mathrm{K}\right)\end{array}$ & $\begin{array}{c}\boldsymbol{h}_{\boldsymbol{e m p} \boldsymbol{p}} \text { Equation } 9 \\
\left(\mathrm{~W} / \mathrm{m}^{2} \cdot \mathrm{K}\right)\end{array}$ & $\begin{array}{c}\text { Error } \\
(\mathbf{\%})\end{array}$ \\
\hline 80 & 7.44 & 5.2 & 30 \\
\hline 75 & 5.9 & 5 & 15 \\
\hline 70 & 10 & 4.7 & 53 \\
\hline 65 & 4.9 & 4.6 & 6 \\
\hline 60 & 4.8 & 4.5 & 6 \\
\hline
\end{tabular}

Table 1. Free convection heat transfer coefficients.

\section{Steady-state Heating Experiments}

Tests consisted of supplying hot gas at a specific Reynolds number $(R e=\rho V D / \mu)$ and temperature ratio $\left(\theta=T_{i n} / T_{a}\right)$, for a chosen liquid volume ratio ( $\left.\mathrm{LVR}=V_{l} / V_{\text {scrubber }}\right)$ and orifice ratio ( $\left.\beta=d_{\text {orifice }} / d_{\text {pipe }}\right)$. The inlet gas temperature was increased by controlling the blower setup, then the previous steps were repeated. After that, the inlet flow rate of hot gas increased, and another set of data was recorded. This procedure continued until the capacity was reached the gas source, for different inlet gas temperatures and flow rates. The calculations of the thermodynamic analysis were achieved based the raw data obtained from the steady state heating experiments.

\section{Inlet Power}

The system receives energy from the inlet gas only, and this energy was calculated using Equation 2. Increasing the inlet gas temperature ratio and/or Reynolds number increased the inlet power because this energy depends on both mass and temperature of the gas components. In Figure 5, the orifice ratio of 0.2 was chosen to show this effect, because at this size several tests were achieved using the same liquid volume ratio, to eliminate this parameter effect.

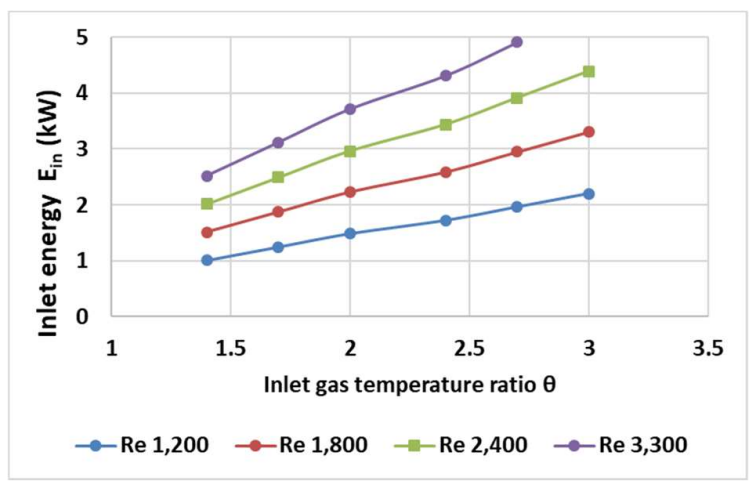

Figure 5. The relation of inlet power and inlet gas conditions.

\section{Outlet Power}

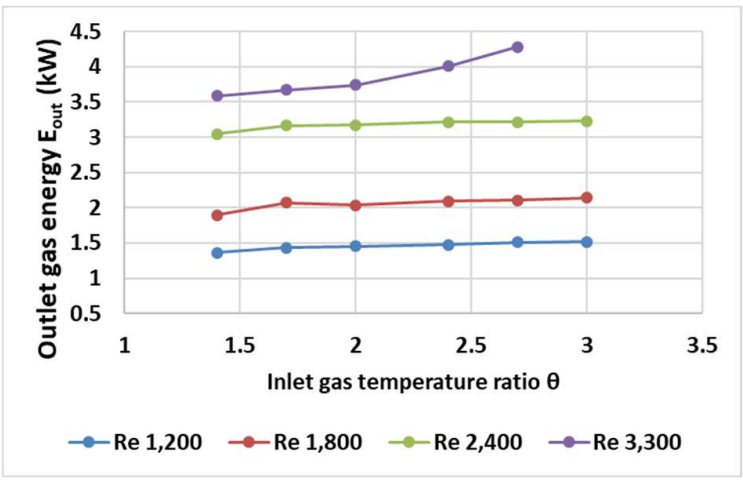

Figure 6 . The relation of outlet power and inlet gas conditions. 
The energy carried out by the gas that was calculated using Equation 3 increased slightly due to increasing the inlet gas $\theta$ (Figure 6). However, the outlet gas energy is independent on liquid volume ratio or the orifice ratio.

\section{Evaporated Power}

The liquid evaporated from the scrubber as a result of hot gas supply at the scrubber inlet. Increasing the inlet gas temperature ratio and/or Reynolds number increased the evaporation rate. The evaporated mass was calculated from the scrubber mass balance. Increasing the liquid evaporation increased the evaporative energy, which was calculated using the Equation 4, as shown in figure 7 .

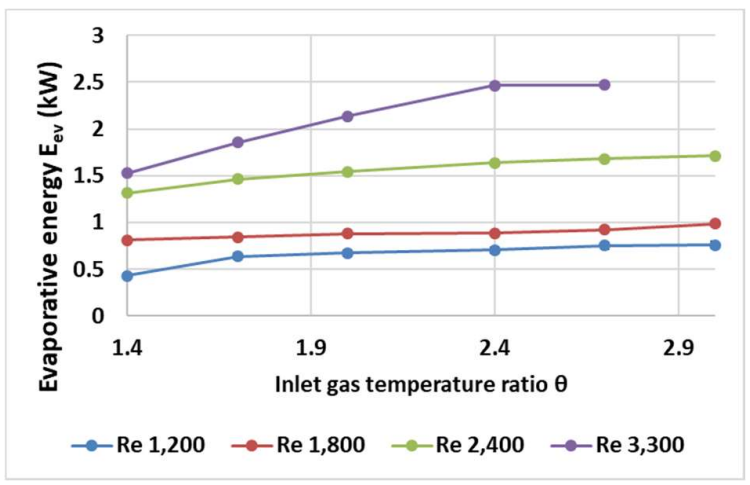

Figure 7. The effect of the inlet gas condition on the evaporative energy.

\section{Outlet Gas Humidity}

The energy loss from the scrubber was estimated based on Equation 7. The theoretical outlet gas energy was calculated based on the energy balance in Equation 1. After that, the outlet gas relative humidity was obtained based on this theoretical outlet gas energy.

During some of the steady-state heating experiments, the calculated outlet gas relative humidity showed an underprediction using the scrubber energy and mass balances in addition to some differences between this $\mathrm{RH}$ and the measured RH by the sensor, as shown in Figure 8 . This could be a result

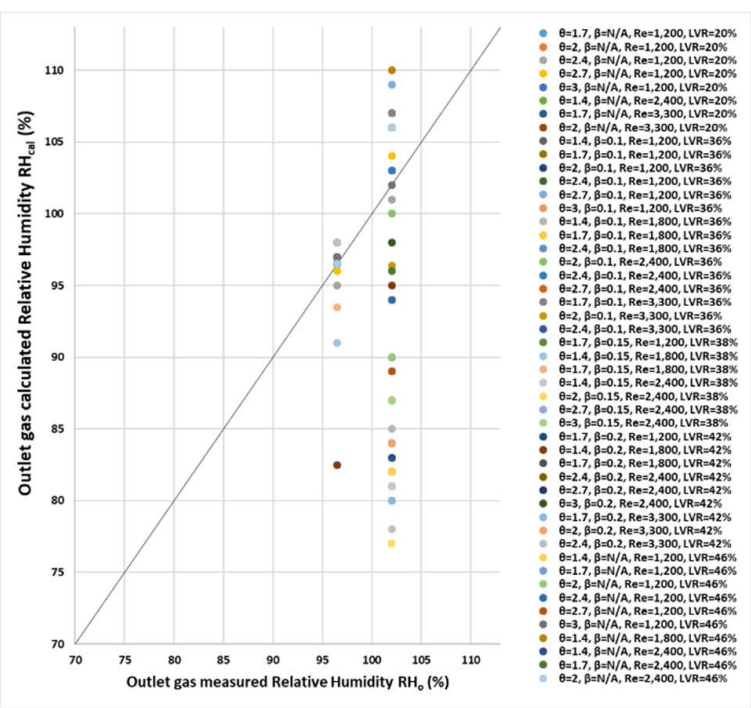

Figure 8 . Outlet gas relative humidity. of the humidity probe uncertainty $( \pm 4 \%)$, as well as the errors caused by heat loss (Equation 7). On average, a $9.85 \%$ error was found between the calculated and measured outlet gas relative humidity.

For some tests of the inlet gas temperatures ratios below 1.7, the measured outlet gas relative humidity values varied between $74 \%$ and $86 \%$, because lower gas energy led to lower vapour saturation. Indeed, increasing the inlet gas $\mathrm{Re}$ and/or $\theta$ would increase the liquid evaporation and hence the outlet gas relative humidity. Further studies is required to improve the estimation of heat loss (Equation 7) and outlet gas relative humidity (Equation 8).

\section{Conclusion}

The presented experimental results confirm that the scrubber effectively reduces the inlet gas temperature from $650^{\circ} \mathrm{C}$ to about $50^{\circ} \mathrm{C}$. However, the outlet gas relative humidity increased due to the high liquid evaporation rate. Adding the orifice plate reduces the turbulence and the liquid leaving the scrubber from the outlet. The thermodynamic analysis shows that increasing the liquid volume ratio reduced the outlet gas temperature. Scrubber performance can be affected by increasing the inlet gas temperature ratio and/or Reynolds number in several ways. In particular, increasing the liquid evaporation and the inlet energies, outlet energies and evaporative energies. However, increasing the liquid volume ratio and/or adding the orifice plate did not affect the leaving energy and the evaporative energy. The gas leaves the scrubber mostly in a saturation condition. Finally, scrubber performance can improve thermodynamically by reducing the inlet gas Reynolds number and/or inlet gas temperature ratio temperature.

\section{Acknowledgments}

The authors gratefully acknowledge the support of Peak3 P/L in collaboration with ARC Linkage grant LP110200158.

\section{References}

[1] Situ, R., Brown, R. J., Wang, H., Surawski, N., Ristovski, Z.D. (2012) Exit humidity of wet scrubbers for underground coal mines. $18^{\text {th }}$ Australasian Fluid Mech. Conf. $3^{\text {rd }}-7^{\text {th }}$ Dec. 2012, Australia.

[2] Zizka, M., Sulc, R., Ditl, P. (2017) Heat transfer between gas and liquid in a bubble column. Chem. Eng. Trans., 57, 1261-1266. doi: 10.3303/CET1757211.

[3] Hoque, N., Situ, R., Hagan, W., Almedia, J., Lin, W., Brown, R. J. (2014) A thermo-fluid study of a diesel engine wet scrubber. $19^{\text {th }}$ Australasian Fluid Mech. Conf. $8^{\text {th }}-11^{\text {th }}$ Dec. 2014, Australia.

[4] O'Sullivan, C. T. (1990) Newton's law of cooling- A critical assessment. Am. J. Phys. 58(10), 956-960. doi: $10.1119 / 1.16309$

[5] Incropera, F.P., DeWitt, D.P. (2002) Fundamentals of heat and mass transfer. J. Wiley, New York.

[6] Abdulwahid, A.A., Situ, R., Brown, R. (2018) Underground diesel exhaust wet scrubbers: Current status and future prospects. Energies, 11, 1-20. doi:10.3390/en1111306. 